\title{
Thresh Effects and Spatial Spillover of Electricity Consumption on Economic Growth
}

\author{
Liping $\mathrm{Guo}^{\mathrm{a}, *}$, Jie Zhou ${ }^{\mathrm{a}}$, Xiaowei Yang ${ }^{\mathrm{b}}$ \\ ${ }^{a}$ State Grid Zhejiang Yuyao Power Supply Company, Yuyao315400, Zhejiang, China \\ ${ }^{b}$ Ningbo City College of Vocational Technology, Ningbo315100, Zhejiang, China
}

\begin{abstract}
The importance of the supply of electricity to economic growth is self-evident. However, the existing research mostly focuses on the linear relationship between electricity consumption and economic growth, while ignoring the nonlinear relationship between them. What's more, the existing research also ignores the spatial correlation of power consumption and its spillover effect on economic growth. In order to address the deficiency of the existing research, this study empirically analyzes the effects of Chinese provincial electricity of economic growth based on the panel threshold model and panel spatial model with 30 provincial samples from 1995 to 2014 . The results show that China's power consumption causes threshold effect and spatial spillover on economic growth. When per capita GDP, per capita consumption expenditure, and per capita investment exceed a certain threshold, the positive role in stimulating economic growth of electricity consumption is significantly different from those of the elasticity when the per capita GDP, per capita consumption expenditure, and per capita investment do not exceed the corresponding thresh value. Not only does the local electricity consumption significantly promote economic growth of the local region, the electricity consumption spillover effects of the adjacent provinces can also promote the economic growth of the local region. If the spatial spillover effect of electricity consumption is neglected, the supportive effect of electricity consumption on economic growth will be underestimated.
\end{abstract}

Keywords: Electricity consumption; economic growth; nonlinear relationship; threshold effect, spatial spillover

(Submitted on January 2, 2017; Revised on April 15, 2017; Accepted on June 13, 2017)

(C) 2017 Totem Publisher, Inc. All rights reserved.

\section{Introduction}

China's economic take-off accompanied by China's power industry development and electricity demand has become another "barometer" of China's economic growth [1]. Statistical data shows that China's gross domestic product (GDP) grew from 57733 billion Yuan to 2015676708 billion Yuan during 1995-2015; meanwhile, the electricity consumption demand of the whole society has increased from 1027.311 billion kilowatts per hour in 1995 to 5588.73 billion kilowatts per hour in 2015 . In the past 20 years, although China's electricity consumption and economic growth rates are not consistent with each other, their absolute amounts show similarly significant characteristics of growth, reflecting their close relationship. A lot of literature focuses on the relationship between economic growth and electricity consumption, but these studies only investigated the linear relationship between them. According to the different types of sample data, these literatures can be divided into two categories:

One category is based on cointegration modelling and Grainger causality analysis with the time series. For example, researchers have verified the existence of the hypothesis on the relationship between China's electricity consumption and

\footnotetext{
* Corresponding author.

E-mail address: lipingguoyy@163.com.
} 
economic growth using cointegration analysis and error correction model with the time series data during 1952-2001. Shiu and Lam applied the error-correction model to examine the causality between electricity consumption and real GDP in China during 1971-2000 and the estimation results indicate that real GDP and China's electricity consumption are cointegrated and there is unidirectional Granger causality from electricity consumption to real GDP but not vice versa. Yuan et al. applied the cointegration theory to examine the causal relationship between electricity consumption and real GDP in China during 19782004 and the estimation results indicate that real GDP and electricity consumption for China are cointegrated and there is only unidirectional Granger causality from electricity consumption to real GDP but not the vice versa. Researchers have confirmed that there existed a long-term equilibrium relationship between China's electricity consumption and the real GDP. Sun and Zhang also confirmed that Granger causality only existed from electricity consumption to economic growth using quarterly data since 2004 [2].

Another category is based on cointegration modelling and error correction analysis with panel data. For example, using the data of 30 provinces and cities in China. Researchers used the panel cointegration method to confirm that the electricity consumption played a significant role in promoting the economic growth of provinces and cities. Using similar methods, Herrerias et al., using inter-provincial data of China from 1995 to 2009, verified the mutual dependence between electricity consumption and economic growth in China [3]. Li et al. [4] confirmed the difference of the relationship in the East and West between electricity consumption and economic growth with inter-provincial data of China from 1990 to 2011; based on the panel error correction model, Liu and Ma not only confirmed the cointegration relationship between China's electricity consumption and economic growth, but also proved the Granger causality from the power consumption to economic growth $[5]$.

Some scholars doubt whether there is a symmetric relationship between electricity consumption and economic growth. Zhang regarded that it would get the misleading results using the vector error correction model if we could confirm the existence of asymmetric adjustment between electricity consumption and economic growth. But using the two-mechanism threshold cointegration test with China's time series data during the years 1955-2009, Zhang didn't find the existence of the nonlinear cointegration relationship between China's electricity consumption and economic growth. This difference in results stems from multiple factors: $\mathrm{Li}$ [4] used the threshold cointegration model integrated with the time series data from 1980 to 2009. He confirmed the existence of the long-term nonlinear relationship between economic growth and China's electricity consumption, the usage efficiency of electricity, electricity prices and other factors; Liang selected the time series during 1953-200 and applied the Markov regime method. The Granger test method also confirmed the existence of the nonlinear relationship between electricity consumption and economic growth in China [6]. Although this nonlinear relationship between electricity consumption and economic growth may be objective, the public may doubt the reliability of the empirical results only with the time series but not the panel data.

In addition, a major flaw in the existing studies on the relationship between electricity consumption and economic growth is that these studies ignore the spatial correlation of different provincial power consumption. According to Anselin, if electricity consumption is in the presence of significant spatial correlation, neglecting the effect of spatial correlation would lead to errors or inconsistencies of estimation. In fact, the literature on the relationship between electricity consumption in other countries has noticed the space related issues of electricity consumption. To our knowledge, only Leticia et al. used the spatial autoregressive model with autoregressive disturbances to analyze the presence of spatial spillover effects in electricity consumption using an aggregate panel data set on the 46 Spanish provinces for the period of 2001 to 2010 [7]. But in their paper they only estimated the price and income elasticity of electricity demand.

In order to provide more convincing evidence for the existence of the nonlinear relationship between electricity consumption and economic growth, this study firstly constructed the panel threshold model to empirically analyze the threshold effect of China power consumption on economic growth. In addition, this study further constructs a panel spatial econometric model to test the spatial spillover effects of electricity consumption to economic growth, which is neglected in the existing literature. The empirical results show that there not only exists significant threshold effects of the provincial electricity consumption on economic growth in China, but also causes spatial spillover effects. When the provincial per capita GDP is more than 42361.703 Yuan, the expenditure of per capita consumption is more than 13082.098 Yuan, and per capita investment is more than 1896.945 Yuan, the effects of electricity consumption on economic growth are strikingly different from the situations when the per capita GDP, per capita consumption and per capita investment are less than the corresponding threshold value. Electricity consumption of the provinces not only plays a promoting effect on the economic growth of local provinces, but also has the spatial spillover effects on the economic growth of neighbouring provinces. Not considering the spatial spillover effects may underestimate the role of electricity consumption in economic growth.

The setup of this article is arranged as follows: the second part contains the research design on models, methodology and data. The third part contains the empirical results and interpretation, and the final part contains the conclusion and policy implication. 


\section{Models, Methodology and Data}

\subsection{The construction of the basic model}

In order to empirically test the relationship between electricity consumption and economic growth, we need to build the corresponding econometric model. We introduced the power consumption (E), capital (K), and labor (L) input as input elements into the production function named Cobb and Douglas, and relaxed the assumption of constant returns to scale. The following is the equation:

$$
Y_{i t}=A_{i t} K_{i t}^{\alpha} L_{i t}^{\beta} E_{i t}^{\gamma}
$$

Whereas $i$ indicates the provincial domain, $t$ represents the period, A is the technology progress, $\mathrm{Y}$ is a measure of economic growth. Greek letters $\alpha, \beta, \gamma$ are parameters to be estimated. The formula (2) is obtained by taking the natural logarithm on both sides of the equation (1):

$$
\log \left(Y_{i t}\right)=\log \left(A_{i t}\right)+\alpha \log \left(K_{i t}\right)+\beta \log \left(L_{i t}\right)+\gamma \log \left(E_{i t}\right)
$$

If we do not consider the influence of other factors, according to formula (2), we can analyze the impact of capital, labor and electricity consumption on the economic growth in a closed economy. However, considering the influence of other factors on the adjustment of China's industrial structure, some control variables need to be added to the formula (2) to build the basic econometric model (3):

$$
\begin{aligned}
\log \left(Y_{i t}\right)= & \log \left(A_{i t}\right)+\alpha \log \left(K_{i t}\right)+\beta \log \left(L_{i t}\right) \\
& +\gamma \log \left(E_{i t}\right)+\psi_{j} \sum_{j=1}^{l} \text { Control }_{j, i t} \\
& +\mu_{i}+\varepsilon_{i t}
\end{aligned}
$$

\subsection{The analytical method of the threshold effect}

We introduce the panel threshold regression method to analyze the nonlinear effect of power consumption on economic growth and the method needs to find the critical point of the mutation. According to [8], assumption only a single threshold, the model can be constructed as follows:

$$
\begin{aligned}
\log \left(Y_{i t}\right)= & c+\alpha \log \left(K_{i t}\right)+\beta \log \left(L_{i t}\right) \\
& +\gamma_{1} \log \left(E_{i t}\right) I\left(\text { Thresh }_{i t} \leq \omega\right) \\
& +\gamma_{2} \log \left(E_{i t}\right) I\left(\text { Thresh }_{i t}>\omega\right) \\
& +\psi_{j} \sum_{j=1}^{l} \text { Control }_{j, i t} \\
& +\mu_{i}+\varepsilon_{i t}
\end{aligned}
$$

Among them, $i$ is the representative function, Thresh is the threshold variable, $\omega$ indicates the corresponding threshold value, and the threshold value is estimated by the grid search method, $\hat{\omega}=\operatorname{argmin} S_{1}(\omega)$.

In model (4), when the critical value exceeds $\omega$, it means that the influencing coefficient of the electric power consumption on economic growth can be changed. It usually needs to construct the F statistic $\left(F=\left(S_{0}-S_{1}(\hat{\omega})\right) / \hat{\sigma}^{2}\right)$ to test the significance of the threshold. In the formula of F, $S_{0}$ is the sum of squares of residuals without a threshold effect, and $S_{1}(\hat{\omega})$ is the residual sum of squares with a threshold effect, and $\hat{\sigma}^{2}$ is the variance of the perturbation term. For the single threshold regression model, the original hypothesis $H_{0}$ indicates that there is no threshold effect, and the alternative hypothesis $H_{1}$ represents that there is only one threshold value. Using the bootstrap method, the asymptotic distribution of the corresponding F statistic and the corresponding probability value can be obtained based on the likelihood ratio $\left(L R(\omega)=\left(S_{1}(\omega)-S_{1}(\hat{\omega})\right) / \hat{\sigma}^{2}\right)$. When the probability value is sufficiently small, the original hypothesis $H_{0}$ is rejected. Otherwise, the alternative hypothesis $H_{1}$ is accepted.

If there exists multiple thresholds, the formula (4) needs to be able to test the existence of the thresholds. Taking the double threshold model as an example, the threshold model can be constructed as the following form: 


$$
\begin{aligned}
\log \left(Y_{i t}\right)=c & +\alpha \log \left(K_{i t}\right)+\beta \log \left(L_{i t}\right) \\
& +\gamma_{1} \log \left(E_{i t}\right) I\left(\text { Thresh }_{i t} \leq \omega_{1}\right) \\
& +\gamma_{2} \log \left(E_{i t}\right) I\left(\omega_{1}<\text { Thresh }_{i t} \leq \omega_{2}\right) \\
& +\gamma_{3} \log \left(E_{i t}\right) I\left(\text { Thresh }_{i t}>\omega_{3}\right) \\
& +\psi_{j} \sum_{j=1}^{l} \text { Control }_{j, i t}+\mu_{i}+\varepsilon_{i t}
\end{aligned}
$$

The methods for judging the double threshold or single threshold are not the same. Usually the threshold value $\hat{\omega}_{1}$ is determined first, and the second threshold value $\hat{\omega}_{2}$ is defined later followed by the minimized sum of squared residual $S_{2}\left(\hat{\omega}_{2}\right)$. When the second threshold value is fixed, we go back to adjust the value of the first threshold value. Next, minimize the sum of squared residuals is updated $S_{1}\left(\hat{\omega}_{1}\right)$. The test method about triple threshold is similar to the double threshold test, and so on.

\subsection{The analytical method of spatial spillover effect}

According to the different approach on spatial panel model setting, the spatial panel model can be divided into two kinds: one is the panel spatial autoregressive model (SAR). The expression is as follows:

$$
\begin{aligned}
\log \left(Y_{i t}\right)=\rho \sum_{j=1}^{N} w_{i j} \log \left(Y_{j t}\right)+\beta_{1} \log \left(K_{i t}\right) \\
+\beta_{2} \log \left(L_{i t}\right)+\beta_{3} \log \left(E_{i t}\right) \\
+\psi_{j} \sum_{j=1}^{l} \text { Control }_{j, i t}+\mu_{i}+\varepsilon_{i t}
\end{aligned}
$$

The panel spatial error model (SEM). The expression is as follows:

$$
\begin{aligned}
\log \left(Y_{i t}\right) & =\beta_{1} \log \left(K_{i t}\right)+\beta_{2} \log \left(L_{i t}\right)+\beta_{3} \log \left(E_{i t}\right) \\
& +\psi_{(j)} \sum_{j=1}^{l} \text { Control }_{j, i t}+\mu_{i}+\varphi_{i t} \\
\varphi_{i t} & =\lambda \sum_{j=1}^{N} w_{i j} \varphi_{j t}+\varepsilon_{i t}
\end{aligned}
$$

In the (6) and (7) model, i denotes the provinces and t denotes the year; the explained variable y is $\mathrm{N} \times \mathrm{T}$ vector and explanatory variables $x(k)$ is $\mathrm{N} \times \mathrm{T}$ vector; $\beta_{(k)}$ and $\psi_{(j)}$ represents the $k$-th and the $j$-th parameter to be estimated respectively; $w_{i j}$ is the element of the spatial weight matrix; $\varepsilon_{i t}$ is the error term with an independent same distribution; zero mean and expectations named $\sigma^{2} ; \mu_{i}$ reflects the effect of a specific space; $\rho$ is the space autoregressive coefficient; $\varphi_{i t}$ is the spatial autoregressive error conditions, and $\lambda$ is the spatial autocorrelation coefficient.

The maximum likelihood estimation method (ML) is usually adopted to estimate the parameters of the spatial econometric model. Because the estimated results are different between the SAR model and the SEM model, it is necessary to determine the merits of the different results. Maximum likelihood value and the Lagrange multiplier method usually are adopted to determine which way is better, the former usually judges according to the logarithm of the maximum likelihood values $(\log \mathrm{L})$, the latter usually judges according to the Lagrange multiplier (LM) statistic value. It is generally considered that the estimated result of the model with larger statistics is better for both of the two methods.

Table 1. Variables description

\begin{tabular}{llll} 
Variables & Code & Index Construction & Unit Name \\
\hline \hline Economic growth & Y & GDP & 100 million Yuan \\
\hline Capital input & $\mathrm{K}$ & newly fixed assets investment & 100 million Yuan \\
\hline Labor input & $\mathrm{L}$ & $\begin{array}{l}\text { number of employees at the end of } \\
\text { the year }\end{array}$ & Ten thousand people \\
\hline Electricity consumption & $\mathrm{E}$ & $\begin{array}{l}\text { electricity consumption of the whole } \\
\text { society }\end{array}$ & $\mathrm{kw} / \mathrm{h}$ \\
\hline
\end{tabular}




\begin{tabular}{llll}
\hline Industrial structure & stru & $\begin{array}{l}\text { secondary and tertiary } \\
\text { industry/primary industry }\end{array}$ & $\%$ \\
\hline Trade openness & open & import and export volume open/GDP & $\%$ \\
\hline Per capita GDP & avgdp & Per capita GDP & Yuan/ people \\
\hline Per capita Consumption & avcon & Per capita consumption & Yuan/ people \\
\hline Per capita investment & avinv & K/ population at the end of the year & $\begin{array}{l}\text { Yuan/ Ten thousand } \\
\text { people }\end{array}$ \\
\hline Weight matrix & $\mathrm{W}$ & $\begin{array}{l}\text { If region } \mathrm{i} \text { is adjacent to region } \mathrm{j}, \\
\mathrm{w}_{\mathrm{ij}}=1 ; \text { Otherwise, } \mathrm{w}_{\mathrm{i} j}=0\end{array}$ & \\
\hline \hline
\end{tabular}

Table 2. Summary statistics of the variables

\begin{tabular}{llllll} 
Variable & Obs & Mean & Std.Dev. & Min & Max \\
\hline \hline $\log (\mathrm{Y})$ & 600 & 8.464 & 1.180 & 5.123 & 11.124 \\
\hline $\log (\mathrm{K})$ & 600 & 7.691 & 1.355 & 4.018 & 10.657 \\
\hline $\log (\mathrm{L})$ & 600 & 7.492 & 0.827 & 5.497 & 8.796 \\
\hline $\log (\mathrm{E})$ & 600 & 6.428 & 0.909 & 3.466 & 8.563 \\
\hline $\log ($ stru $)$ & 600 & 1.970 & 0.893 & 0.556 & 5.235 \\
\hline $\log ($ open $)$ & 600 & -1.761 & 1.013 & -3.442 & 0.718 \\
\hline $\log$ (avgdp) & 600 & 9.554 & 0.902 & 7.510 & 11.564 \\
\hline $\log$ (avcon) & 600 & 8.598 & 0.766 & 7.098 & 10.669 \\
\hline $\log$ (avinv) & 600 & 8.777 & 1.169 & 6.205 & 11.159 \\
\hline \hline
\end{tabular}

\subsection{Data source and variables description}

In this paper, 30 provinces (except for Tibet) are selected as the research objects. The sample period begins in 1995 and ends in 2014. Basic data comes from the Chinese National Bureau of Statistics website column and Chinese Economic and Social Development Statistics Database. The variables in this paper are described in Table 1. It's necessary to point out that setting the value of elementary elements to $0-1$ adjacency spatial weight matrix W accords to geographic adjacent or not. If province $\mathrm{i}$ is geographically adjacent to region $\mathrm{j}, \mathrm{w}_{\mathrm{ij}}=1$; Otherwise, $\mathrm{w}_{\mathrm{ij}}=0$. The geographic adjacent information of 30 provinces comes from “The Map of People's Republic of China". Table 2 shows the summary statistics of the variables.

\section{Empirical Results and Analysis}

\subsection{The results of panel threshold regression}

According to [9], we firstly tested whether there exists a single threshold, double threshold, triple threshold condition or not when the power consumption effects on economic growth. Table 3 lists the corresponding F statistics values, probability values and the corresponding critical value at 1\%, 5\%,10\% significant level when the threshold variable is per capita GDP $\log ($ avgdp), per capita consumption $\log ($ avcon) and investment per capita $\log ($ avinv) with single threshold, double threshold or triple threshold, respectively.

As Table 3 shows, in the process of threshold model test with threshold variables named GDP per capita, we firstly tested whether there is a single threshold model or not. Because the probability of accepting the null hypothesis $\mathrm{H}_{0}$ "linear model" is 0.000 , therefore the alternative hypothesis $\mathrm{H}_{1}$ "single threshold model" is accepted; we further tested double threshold model whether there exists a double threshold model or single threshold model. Because of the accepting probability, the null hypothesis $\mathrm{H}_{1}$ is 0.070 ; therefore, it should accept the null hypothesis at the 5\% significance level. Finally, the results show that it should accept the conclusion of "single threshold".

Similarly, when per capita consumption is the threshold variable, it should refuse the null hypothesis "linear model" at $1 \%$ significance level, while accepting the alternative hypothesis of "single threshold model"; For the double threshold test, the accepting probability of single threshold hypothesis is $0.150, \mathrm{~F}$ statistic value below the critical value at the $1 \%, 5 \%$ or $10 \%$ of significance level. So, the null hypothesis should be accepted. That is to say, when per capita consumption is acted as the threshold variable, the single threshold model maybe the best choice. 
Table 3. Test for threshold effects

\begin{tabular}{lllll}
$\begin{array}{l}\text { Threshold } \\
\text { variable }\end{array}$ & Test assumption & F-statistics & P-value & $\begin{array}{l}\text { Critical values } \\
1 \%, 5 \%, 10 \%\end{array}$ \\
\hline \hline \multirow{3}{*}{$\log ($ avgdp) } & $\mathrm{H}_{0}$ : None threshold; $\mathrm{H}_{1}$ : Single threshold & 121.530 & 0.000 & $47.793,34.730,29.975$ \\
& $\mathrm{H}_{0}$ : Single threshold; $\mathrm{H}_{1}$ : Double threshold & 31.960 & 0.070 & $55.178,36.901,25.481$ \\
& $\mathrm{H}_{0}$ : Double threshold; $\mathrm{H}_{1}$ : Triple threshold & 16.450 & 0.647 & $62.212,48.780,40.987$ \\
\hline \multirow{3}{*}{$\log ($ avcon $)$} & $\mathrm{H}_{0}$ : None threshold; $\mathrm{H} 1$ : Single threshold & 114.780 & 0.000 & $51.678,39.214,32.058$ \\
& $\mathrm{H}_{0}$ : Single threshold; $\mathrm{H}_{1}$ : Double threshold & 28.870 & 0.150 & $48.134,39.307,30.724$ \\
& $\mathrm{H}_{0}$ : Double threshold; $\mathrm{H}_{1}$ : Triple threshold & 12.550 & 0.837 & $61.186,47.120,40.933$ \\
\hline \multirow{3}{*}{$\log ($ avinv) $)$} & $\mathrm{H}_{0}$ : None threshold; $\mathrm{H} 1$ : Single threshold & 34.560 & 0.053 & $50.442,34.809,29.261$ \\
& $\mathrm{H}_{0}$ : Single threshold; $\mathrm{H}_{1}$ : Double threshold & 17.190 & 0.247 & $39.006,28.659,23.315$ \\
& $\mathrm{H}_{0}$ : Double threshold; $\mathrm{H}_{1}$ : Triple threshold & 16.120 & 0.273 & $40.137,26.965,22.545$ \\
\hline \hline
\end{tabular}

When per capita investment is taken as the threshold variable, it seems that we should accept the "linear model" null hypothesis at $1 \%$ and $5 \%$ significance level, but at the $10 \%$ level of significance, the result refuses the null hypothesis $\mathrm{H}_{0}$ and accepts the alternative hypothesis $\mathrm{H}_{1}$ of "single threshold model"; while for the two threshold test, the probability of the single threshold hypothesis is 0.247 and the F statistics is less than the critical value at $1 \%, 5 \%$ or $10 \%$ significance level. So, it should accept the null hypothesis. That is to say, using the single threshold model to estimate the coefficient is the best choice when per capita investment is the threshold variable.

Table 4 lists the threshold value of $\log (\operatorname{avgdp}), \log ($ avcon $)$ and $\log$ (avinv) obtained by the grid search method in the single threshold model. From Table 4, we can draw the conclusion that the threshold value of per capita GDP, per capita consumption and per capita investment is 10.654 (avgdp=42361.703), 9.479 (avcon =13082.098) and 7.548 (avinv $=1896.945)$, respectively.

Table 4. The estimated threshold value

\begin{tabular}{llll} 
Threshold variable & Test results & Threshold value & Confidence Interval (95\%) \\
\hline \hline $\log$ (avgdp) & single threshold & 10.654 & {$[10.619,10.665]$} \\
\hline $\log$ (avcon) & Single threshold & 9.479 & {$[9.471,9.483]$} \\
\hline $\log$ (avinv) & Single threshold & 7.548 & {$[7.489,7.574]$} \\
\hline \hline
\end{tabular}

The panel data model can be divided into the fixed effect model and random effect model according to the difference of the residual component. According to [10], the fixed effect model is a better choice when the regression analysis of the sample is limited to some particular individuals [9]. The regression results in Table 5 are based on the panel fixed effect. The first column in Table 5 is the results of ordinary linear regression, the second column in Table 5 is the threshold regression results based on the threshold variable named per capita GDP, the third column in Table 5 is the threshold regression results based on the threshold variable named per capita consumption, the fourth column in Table 5 is the threshold regression results based on the threshold variable named per capita investment.

The result of linear regression model shows that the variables named $\log (\mathrm{K}), \log (\mathrm{L})$ and $\log (\mathrm{E})$ are in a significantly positive relationship with $\log (\mathrm{Y})$, and the sum of the elasticity is 1.046 . Because the sum of elasticity of capital China, labor and electricity consumption to the output elasticity is greater than 1 , indicating in returns to scale stage of increasing. Further analysis of three nonlinear single threshold regression model, we find that the effects of electricity consumption on economic growth are different when the per capita GDP, per capita consumption and per capita investment are more than or less than the corresponding threshold values.

When the per capita GDP is not more than 42361.703 Yuan, the elasticity of electricity consumption to economic growth is 0.321 ; and when the per capita GDP is more than 42361.703 Yuan, the elasticity of the power consumption to economic growth is 0.350 . However, when the per capita consumption is not greater than 13082.098 Yuan, the elasticity of electricity consumption to economic growth is 0.319 ; and when the per capita consumption is more than 13082.098 Yuan, the elasticity of electricity consumption to economic growth is 0.346 . When the per capita investment is not more than 1896.945 Yuan, the elasticity of electricity consumption to economic growth is 0.339 ; while the per capita investment is more than 1896.945 Yuan, the elasticity of electricity consumption to economic growth is 0.319 . The estimation results show that there exist the "threshold" characteristics when electricity consumption affects economic growth. That is to say, when the per capita GDP, per capita consumption and per capita investment exceed a specific value, the marginal output of electrical consumption will 
change. But further comparing the parameter size before and after threshold, we find that per capita GDP and per capita consumption for threshold estimation of electricity consumption of the marginal output elasticity is increasing, while per capita investment for the elasticity of marginal output of electricity consumption for threshold estimation is reversed, which indicates that the marginal output rate decreased when a large number of new investments drive the growth of the electricity consumption.

\begin{tabular}{|c|c|c|c|c|}
\hline & Threshold(None) & Threshold (log(avgdp)) & Threshold(log(avcon) $)$ & Threshold (log(avinv)) \\
\hline \multirow{2}{*}{$\mathrm{c}$} & $0.926^{* * * *}$ & 0.340 & 0.343 & -0.868 \\
\hline & [12.500] & {$[0.900]$} & {$[0.910]$} & {$[-2.330]$} \\
\hline \multirow{2}{*}{$\log (\mathrm{K})$} & $0.634^{* * *}$ & $0.482^{* * * *}$ & $0.481^{* * * *}$ & $0.515^{* * *}$ \\
\hline & {$[56.760]$} & {$[36.240]$} & {$[36.050]$} & [37.160] \\
\hline \multirow{2}{*}{$\log (\mathrm{L})$} & $0.377^{* * *}$ & $0.322^{* * *}$ & $0.324^{* * *}$ & $0.453^{* * *}$ \\
\hline & [32.250] & [5.910] & {$[5.960]$} & {$[8.140]$} \\
\hline \multirow{2}{*}{$\log (\mathrm{E})$} & $0.035^{* * *}$ & & & \\
\hline & {$[3.050]$} & & & \\
\hline \multirow[b]{2}{*}{$\gamma_{1} \log (\mathrm{E})$} & & $0.321^{* * *}$ & $0.319^{* * * *}$ & $0.339^{* * *}$ \\
\hline & & {$[14.500]$} & {$[14.380]$} & {$[14.250]$} \\
\hline \multirow{2}{*}{$\gamma_{2} \log (\mathrm{E})$} & & $0.350^{* * * *}$ & $0.346^{* * *}$ & $0.319^{* * *}$ \\
\hline & & [15.650] & {$[15.520]$} & [13.560] \\
\hline \multirow{2}{*}{$\log ($ stru $)$} & $0.642^{* * * *}$ & $0.424^{* * *}$ & $0.459^{* * *}$ & $0.546^{* * *}$ \\
\hline & {$[5.460]$} & {$[2.730]$} & [2.930] & {$[2.980]$} \\
\hline \multirow{2}{*}{$\log ($ open $)$} & $0.163^{* * *}$ & 0.008 & 0.003 & 0.001 \\
\hline & [19.550] & {$[0.510]$} & {$[0.170]$} & {$[0.040]$} \\
\hline $\mathrm{R}^{2}$ & 0.978 & & & \\
\hline $\operatorname{adj} R^{2}$ & 0.977 & & & \\
\hline $\mathrm{F}(6,564)$ & & $5668.74^{* * * *}$ & $5667.90^{* * *}$ & $5002.61^{* * *}$ \\
\hline $\mathrm{R}^{2}$ : within & & 0.9837 & 0.9837 & 0.9816 \\
\hline between & & 0.8995 & 0.8987 & 0.8731 \\
\hline overall & & 0.9371 & 0.9366 & 0.9229 \\
\hline
\end{tabular}

Note: $* * *$ indicates significance at the $1 \%$ level, and the data in the square brackets is the t statistics value.

In addition, due to independently explained variables such as $\log (\mathrm{K}), \log (\mathrm{L}), \log (\mathrm{stru})$ and $\log ($ open $)$, the regression coefficients are still positive, and it is similar to the conclusion made from the linear regression model. It confirms that input of capital and labor and industry structure play promoting roles in economic growth and the role of foreign trade promoting economic growth needs to be further verified.

\subsection{The results of spatial panel regression}

The results in Table 6 are obtained by using the maximum likelihood method (ML) combined with the 0-1 adjacency matrix to estimate models (6) and (7). The calculation results of Log L statistics, LM statistics and Robust LM statistics are also listed in Table 6. The Log L statistic value shows that the SAR model, under the condition of spatial fixed effects, is better than the estimation results based on the SEM model with the fixed time. However, the SEM model with space and time fixed effect are better than the corresponding estimation results based on the SAR model. Further testing of the estimated results according to the $\mathrm{LM}_{\mathrm{SAR}}$ and $\mathrm{LM}_{\mathrm{SEM}}$, Robust $\mathrm{LM}_{\mathrm{SAR}}$ and Robust $\mathrm{LM}_{\mathrm{SEM}}$ statistics gives results that are completely consistent with the Log L statistics' results. Therefore, this paper selects model SAR (1), SEM (2) and SEM (3) to explain the spillover effects of electricity consumption and other factors on economic growth.

In the SAR model (1), the estimated parameters of $\mathrm{W} * \log (\mathrm{Y})$ reflecting the spatial correlation is 0.193 at the $1 \%$ level of significance. In the SEM model (2) and SEM model (3), the estimated parameters of the variable named spat.err reflecting the of the spatial correlation also meets $1 \%$ level of the significance, which indicates China's economic growth in the presence of strikingly spatial correlation, and also indicates the how previous studies neglected the spatial effects. 
Table 6. Regression results of spatial models

\begin{tabular}{|c|c|c|c|c|c|c|}
\hline & $\operatorname{SAR}(1)$ & SEM(1) & $\operatorname{SAR}(2)$ & $\operatorname{SEM}(2)$ & $\operatorname{SAR}(3)$ & $\operatorname{SEM}(3)$ \\
\hline \multirow{2}{*}{$\log (\mathrm{K})$} & $0.355^{* * *}$ & $0.427^{* * *}$ & $0.598^{* * *}$ & $0.621^{* * * *}$ & $0.368^{* * * *}$ & $0.455^{* * *}$ \\
\hline & [27.663] & [40.351] & [64.980] & [73.399] & [41.542] & [43.729] \\
\hline \multirow{2}{*}{$\log (\mathrm{L})$} & $0.245^{* * *}$ & $0.268^{* * *}$ & $0.417^{* * *}$ & $0.408^{* * *}$ & $0.281^{* * * *}$ & $0.316^{* * *}$ \\
\hline & {$[6.574]$} & {$[6.564]$} & [37.949] & [38.441] & [7.279] & [7.074] \\
\hline \multirow{2}{*}{$\log (E)$} & $0.182^{* * *}$ & $0.252^{* * *}$ & $0.034^{* * *}$ & $0.022^{* * *}$ & $0.179^{* * * *}$ & $0.259^{* * *}$ \\
\hline & [9.871] & [14.448] & {$[3.155]$} & {$[2.220]$} & [10.707] & 13.543] \\
\hline \multirow{2}{*}{$\log ($ stru $)$} & $0.372^{* * *}$ & $0.407^{\text {**** }}$ & $0.159^{* * * *}$ & $0.153^{* * *}$ & $0.329^{* * *}$ & $0.359^{* * *}$ \\
\hline & [19.952] & [17.993] & [12.491] & [12.406] & [18.853] & 16.447] \\
\hline \multirow{2}{*}{$\log ($ open $)$} & $-0.045^{* * * *}$ & $-0.026 *$ & $0.112^{* * *}$ & $0.104^{* * *}$ & $0.115^{* * *}$ & $0.108^{* * *}$ \\
\hline & {$[-4.025]$} & {$[-1.904]$} & [12.101] & [10.455] & [13.156] & [11.361] \\
\hline \multirow{2}{*}{$\mathrm{W}^{*} \log (\mathrm{Y})$} & $0.193^{* * *}$ & & $0.021^{* *}$ & & $0.194^{* * *}$ & \\
\hline & [8.299] & & [2.186] & & {$[33.255]$} & \\
\hline \multirow{2}{*}{ spat.err. } & & $0.439^{* * *}$ & & $0.375^{* * *}$ & & $0.322^{* * *}$ \\
\hline & & [10.426] & & [8.422] & & [6.950] \\
\hline spatial fixed effects & yes & yes & no & no & yes & yes \\
\hline time period fixed effects & no & no & yes & yes & yes & yes \\
\hline $\mathrm{R}^{2}$ & 0.996 & 0.995 & 0.980 & 0.982 & 0.995 & 0.994 \\
\hline $\operatorname{sigma}^{\wedge} 2$ & 0.006 & 0.007 & 0.028 & 0.025 & 0.006 & 0.009 \\
\hline $\log -\mathrm{L}$ & 703.152 & 625.742 & 220.931 & 246.56 & -358.88 & 570.373 \\
\hline $\mathrm{LM}_{\text {sar }}$ & $281.687^{* * *}$ & & 0.130 & & $25.007^{* * *}$ & \\
\hline Robust $\mathrm{LM}_{\text {sar }}$ & $214.591^{\text {**** }}$ & & 0.723 & & 1.9734 & \\
\hline $\mathrm{LM}_{\mathrm{sem}}$ & & $67.144^{* * *}$ & & $37.166^{* * * *}$ & & $52.373^{* *}$ \\
\hline Robust $\mathrm{LM}_{\mathrm{sem}}$ & & 0.048 & & $37.759^{* * * *}$ & & $29.339^{* *}$ \\
\hline
\end{tabular}

Note: *,**,*** indicate significance at the $10 \%, 5 \%$ and $1 \%$ level respectively, and the data in the square brackets are the t statistics value.

In the SAR model (1), the direct effect of the provincial electricity consumption on economic growth is 0.182 , and the spillover effect of the neighborhood electricity consumption on the local economic growth is $0.035(=0.182 * 0.193)$. Two effects is 0.217 , which means for every $1 \%$ growth in electricity consumption of the local province and the neighboring provinces, the economic growth of local province will grow by $0.217 \%$. In the SEM model (2), all of the explanatory variables meet the t-test. The influencing coefficient of electricity consumption on economic growth is 0.022 . The estimated parameter of spat.err. is 0.375 , which indicates that there exists spillover of the electricity consumption in the adjacent region on economic growth, and its size is about $0.008(=0.022 * 0.375)$. So, the direct effects and spatial spillover promote role is 0.030 . Similarly, in the SEM model (3), the direct effect of the local province electricity consumption on economic growth is 0.259 , and adding the corresponding spatial spillover effect $0.083(=0.259 * 0.322)$, the total effects of electricity consumption on economic growth is 0.342 . The above analysis shows that if the spatial spillover effect is neglected, the promotional role of electricity consumption on economic growth would be underestimated.

Further investigation of the estimated parameters of the other variables, the regression coefficients of $\log (\mathrm{K})$ on economic growth is at intervals between 0.355 to 0.621 and the regression coefficients of $\log (\mathrm{L})$ on economic growth is at intervals between 0.245 to 0.417 , which indicate that capital and labor both promote economic growth. The industrial structure optimization index as a control variable, the regression coefficients of $\log$ (stru) are at intervals between 0.153 to 0.372 , which indicate that the industrial structure of the adjustment and optimization is conducive to economic growth. The effect of foreign trade on economic growth in the Model SAR (1) is significantly negative, while the estimated coefficient of $\log ($ open) on the economic growth in the model SEM (2) and SEM (3) are both positive, which shows that the relationship between foreign trade and economic growth may be uncertain. That is to say that the choice of the econometrics model played a very important role in the empirical results. 


\section{Conclusions}

This study empirically analyzes the effects of China's power consumption to economic growth based on the panel threshold model and panel spatial model with 30 provincial samples during 1995-2014, and two conclusions are made:

(1) The promotional role of Chinese provincial power consumption to economic growth with nonlinear conversion mechanism, and the promotional effects are effected and restricted by the economic basis of the province, per capita consumption and per capita investment level. When a provincial per capita GDP and per capita consumption are more than 42361.703 Yuan and 13082.098 Yuan respectively, the supporting role of electricity consumption on economic growth is strikingly greater than that the per capita GDP and per capita consumption are lower than the corresponding threshold value; while per capita investment is more than $\$ 1896.945$, the supporting role of electricity consumption in economic growth is lower than the effect of that when the per capita investment is less than the corresponding threshold value.

(2) There exists a significant spatial correlation between the economic growth of different provinces. Electricity consumption of different provinces has a direct impact on local economic growth, but also has a spillover effect on the economic growth of neighboring provinces. What's more, the more neighboring provinces, the more the growth spillover may be from the electricity consumption of neighboring provinces. If we ignore the spatial spillover effect of electricity consumption on economic growth coming from the adjacent provinces, it is, to some extent underestimating the effects of China's electricity consumption on local economic growth.

There is no doubt that this paper broadens people's understanding of the mechanism of electricity consumption to economic growth. The above conclusions have important implication for the corresponding policy adjustments. Because the electricity consumption has significant growth effects, it is necessary to fully meet the demand for electricity production and life in order to maintain steady economic growth; because the electricity consumption of different provinces has significant spatial spillover effects, each province should pay full attention to the role of spatial association of electricity consumption in different provinces, and get rid of the artificial segmentation of the electricity consumption market. The cooperative distribution of cross regional transport may secure the electricity supply for the electricity consumption of production and life in the local and adjacent region; taking into account the limited amount of electricity supply, the control strategy of electricity consumption should take into account the differences and dynamics of regional economic conditions. If the electricity demand sharply increases too much for investment, it is necessary to control the electricity consumption and prioritize regions with high marginal output.

\section{References}

1. Sun, X. D and Zhang, L.L., "Electric power consumption and economic growth: a causal analysis based on quarterly data", Journal of North China Electric Power University, no.5, pp. 34-38, 2015.

2. Feng J J, Chen B P, Ma D C, Meng F L., "Comparative study of relationship between electricity consumption and economic growth of China and US based on cointegration analysis", Resource Development \& Market, vol. 32, no. 3, pp. 288-292, 2016.

3. Herrerias M. J., Joyeux, R. and Girardin E., "Short-and long-run causality between energy consumption and economic growth: evidence across regions in China", Applied Energy, vol. 112, no. 4, pp.1483-1492, 2013.

4. Li, Q., Wang, H.C. and Hu, A.G., "China's electricity consumption and economic growth: a causal analysis of China's provincial panel data", China Industrial Economy, no.9, pp. 19-30, 2013.

5. Liu. L. and Ma X.Q., "The correlation between regional economic growth and electricity consumption", Systems Engineering, no. 6, pp. 84-90, 2015.

6. Bernard Njindan Iyke., "Electricity consumption and economic growth in Nigeria: A revisit of the energy-growth debate", Energy Economics, vol. 51, pp. 166-176, 2015.

7. Liang, J.W., "Relationship between energy consumption and economic growth from the perspective of nonlinear", Doctor Dissertation of Tianjin University, 2013.

8. Leticia, M., Blázquez, G., Massimo, F. and Fabian, H., "Regional impact of changes in disposable income on Spanish electricity demand: A spatial econometric analysis", Energy Economics, vol.40, no. 6, S58-S66, 2013.

9. Wang, Q.Y., "Fixed-effect panel threshold model using Stata", The Stata Journal, vol. 15, no.1, pp. 121-134, 2015.

10. Baltagi, B.H., "Econometric Analysis of Panel Data (Fifth Edition)”, Chichester, United Kingdom: John Wily \& Sons, 2013. 